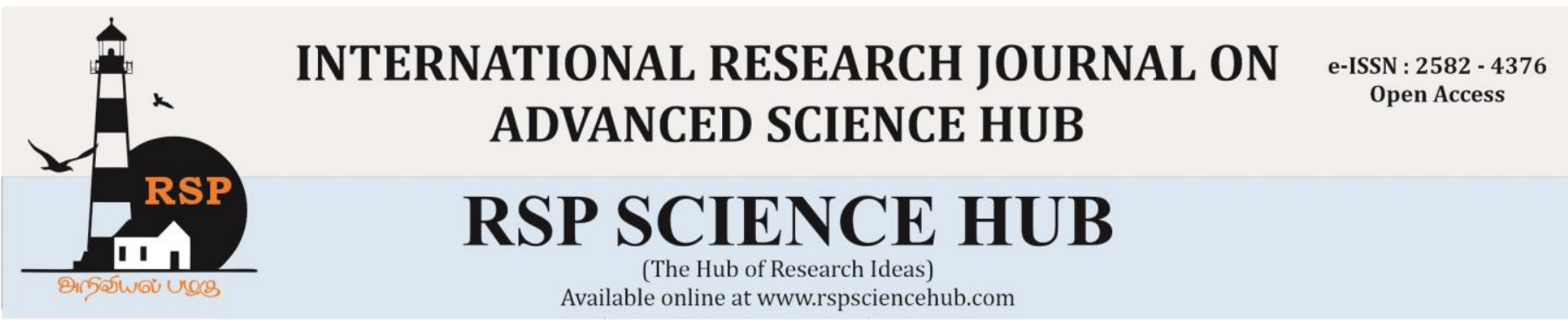

\title{
Implementing the Digital Learning
}

\section{Shubhangi Taneja}

Master of Mathematics, from Maharishi Dayanand University, Rohtak, Harayana, India. shubhangitaneja50@gmail.com

\begin{abstract}
Digital leaning is all about when we are imparting instructions with the use of technology. It helps in today scenario a lot where everywhere is lockdown and increase of COVID-19 cases, the learning and teaching process is not carrying forward in effective way. So, digital learning gives us a platform to provide knowledge of a subject by using means of different applications. This paper deals with the how digital learning helpful in the learning - teaching process of science. In this context also deals with the results of the survey of Class 6 to 10 that how much they prefer digital learning especially in science subject and conclusion of the whole paper that how to overcome some barriers in digital learning.
\end{abstract}

Keywords: Digital learning, teaching, science, applications etc.,

\section{Introduction}

When we talking about today's education, we want to be use more digitalised platform rather than stuck in only one method of teaching. There are many methods of teaching of science like exploratory method, demonstrative method, experiential learning etc. So we teachers and educators should understand the today scenario and focused on digital learning. Digital application like zoom app, Google meet, Cisco WebEx for conducting online classes so teachers must be aware about all these apps and how to use it.

\subsection{Literature review:}

The studied of various papers in this theme suggests that to make digital learning more prominent in science we have to focus on its curriculum development and also application should be free of cost and easy to available to impart teaching of science in a productive way. Sometimes teachers are also not properly trained in providing digital learning to students as some teachers don't have knowledge about the various digital platforms. [1-3] 1.2 Objectives of the study:

1. To understand how much student curious about the digital learning.
2. To compare between the digital learning before and after the COVID-19 period.

3. To understand what are the barriers in digital learning and some limitations of it.

\section{Definition of digital learning:}

Digital learning means when a person is imparting instructions to the students with the use of technology. In a simpler manner, the teacher be more digitalized in this COVID -19 scenario. Online teaching is the only way to engage students in learning more effectively.

\subsection{Features of Digital learning:}

\section{Proper Equipments:}

The teachers who are taking online classes should have proper equipment for that.

\section{Internet Connectivity:}

For smooth flowing of online classes it is very important that internet speed should be high and the network issues were not there. 


\section{Proper training:}

Proper training should be provided to the teachers so that they know how to carry on with the digital learning.

\section{Teaching Methodology:}

Teacher must understand and in online classes it is very essential to use various methodologies in online teaching. Teachers must use blended learning.

\section{Involve Students In Online Learning:}

The main feature of the digital learning is to involve students and increase their curiosity towards the subject.

\section{Interaction:}

With the continuous flow of online classes, teachers must take care of the point to interact with the students by putting prompting questions from them.

\subsection{Comparison of digital learning before and after the COVID -19 scenarios:}

As we all know COVID -19 effect all the fields and in education sector it has a major effect as schools are shut down students are locked in their houses so in this scenario comes the online platform of learning, which engage students in the learning. Before COVID -19 period schools are running smoothly but now a time it's come to learning from digital platforms students are getting knowledge but some how teachers cannot use experimental learning if we talking about teach chemistry topics. But it's a challenge for the schools as well as teachers to continue learning in this critical time also. But we have to take care of that this learning is provided to each and every student even of rural areas as urban are well settled up.

\subsection{Method of study:}

I Prepare the questionnaire related to survey in which I choose the students of class 6 to 10 for filling this online survey form. This form contains questions based on how much students like the digital platform or how much hours they devoted to the online platform.

\subsection{Results:}

The results of the survey show that approx. $45 \%$ of Students like digital learning and they engage themselves at least 5 hours a day. It means that students like this digital platform-based learning. The mostly $95 \%$ of the students use Zoom App for online learning, so that this concludes that in this COVID-19 era we are somehow successful in engaging students in effective manner.

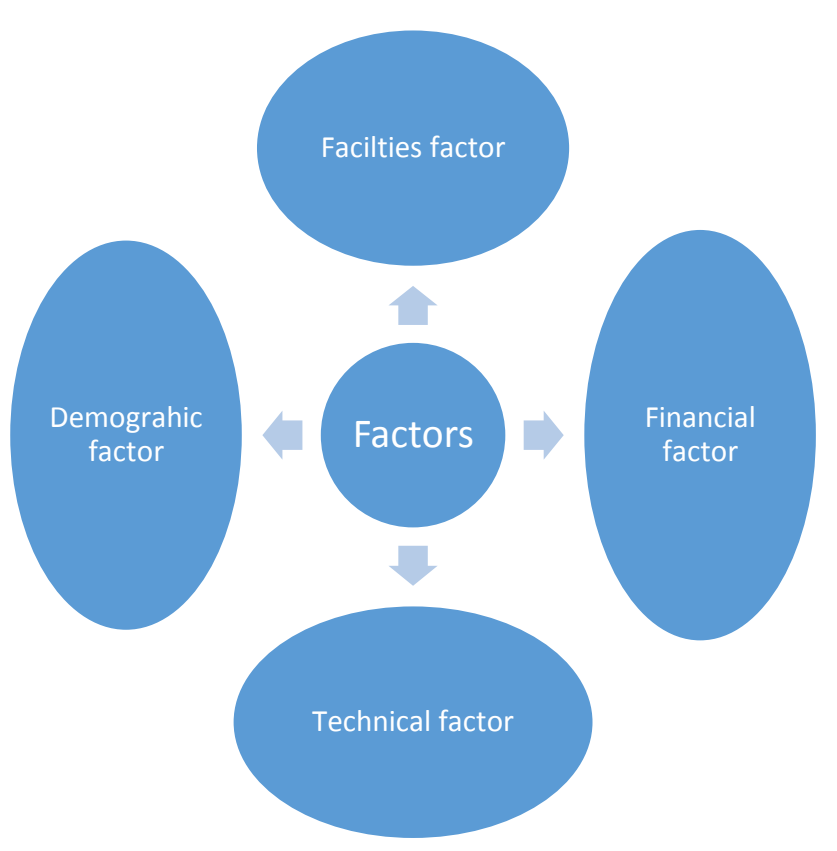

Fig.1. Factors affecting the digital learning

\section{Applications of Digital Leaning}

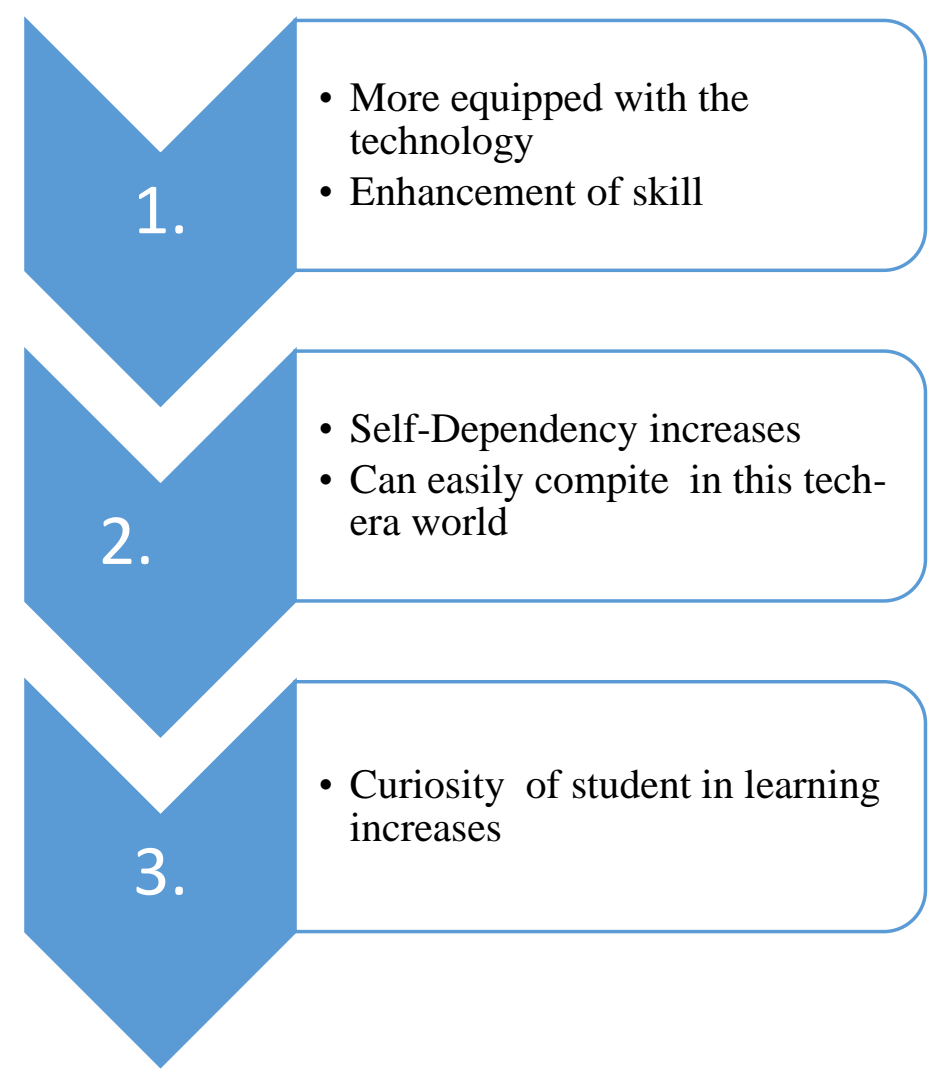

Fig.2 Applications of Digital Leaning 
4. Limitations of Digital Learning:

\section{Lack of Discipline:}

In online classes you cannot control the students because of a virtual interface.

2. Spending time in front of a computer can harm eyes:

Computer screen contains harmful blue screen which harm our vision to see.

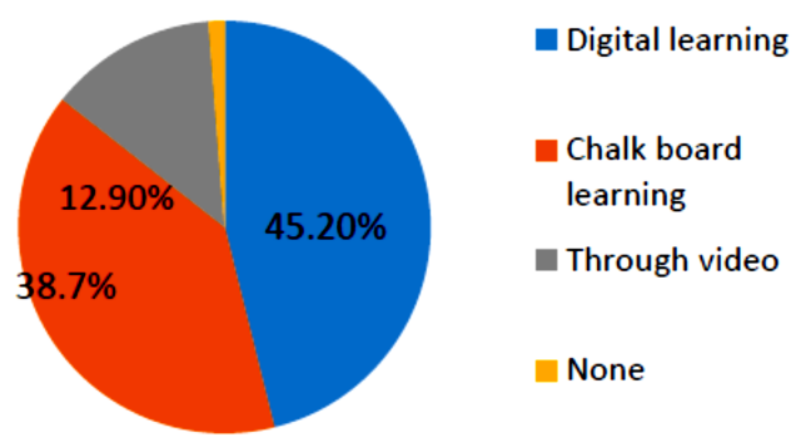

Fig.3. Shows the percentage of students like digital learning

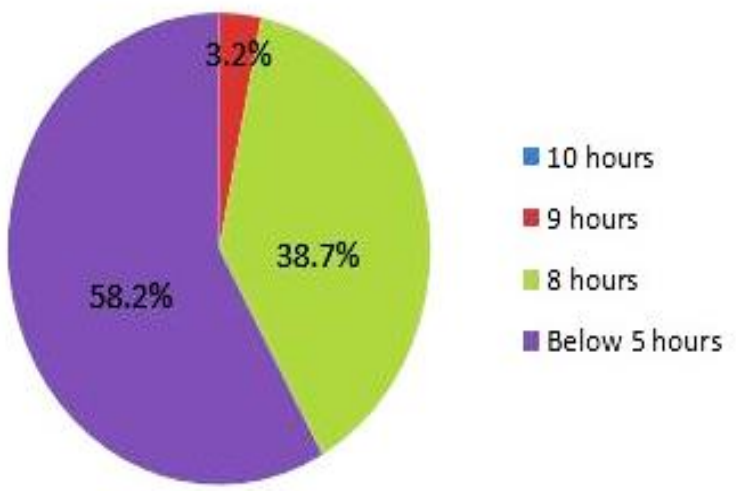

Fig.4. shows that how much hour's students spend time on digital platforms

\section{Lack of communication skill causes failure of learning:}

In an online learning, sometimes students feel shy to raise their doubts so teacher cannot read their faces to get successful learning of a subject.

4. Network Issues: In online classes there is always a problem related to network because in a mid-way of class network issues happen sometimes from student side or teacher side and better understanding of subject doesn't takes place.

\section{Cheating cannot be controlled:}

When teachers are taking online exams you cannot control cheating so actual assessment is never be achieved.

\section{Concentration Factors:}

Sometimes student are not focussing on the classes they get busy on other applications like Facebook, Instagram etc., and shows only their presence their zoom applications.

\section{Get habit of mobiles/laptops:}

Teachers/Students both get used to mobiles and laptops because they are spending so much of timings on it.

\section{Flexibility is somehow low:}

Flexibility in digital learning is low in adequacy because you cannot meet the each and every learning need of student.

Except all the limitations, in today scenario this digital learning is very convenient to involve students in learning and keep involve teachers to update their knowledge in this technology-based world.

\section{Conclusions}

Digital learning is very essential in the $21^{\text {st }}$ century especially for the school it is a boon. It has some pros and cons but still it plays a major role in imparting instructions and engaging students successfully. But we have to work on rural areas where this digital learning is not able to reach because of some barriers. Even we have to provide proper training to the teachers how to use this digital platform.

\section{References \\ Journals}

[1] Av Wire, H.E. (2016). ,Emerging trends in Science Education in a Dynamic Academic Environment, Vol.2 , 2222-1735

[2] Jonathan, Osborne (2015).. Current Trends in Science Education.

[3] "Enhancing learning and teaching through the use of digital technology", ProceedingsSeptember,2016, ISBN: 978-178652-173-7 